\title{
Penerapan Metode Market Basket Analysis pada Minimarket Toko Baru
}

\author{
Rizky Bayu Novrianto ${ }^{\mathrm{a}, 1}$, Muslim $^{\mathrm{a}, 2}$ \\ ${ }^{a}$ Universitas Muslim Indonesia, Jln. UripSumoharjo Km.5, Makassar 90231, Indonesia \\ ${ }^{1}$ rizkybayu00@gmail.com; ${ }^{2}$ Muslim@umi.ac.id
}

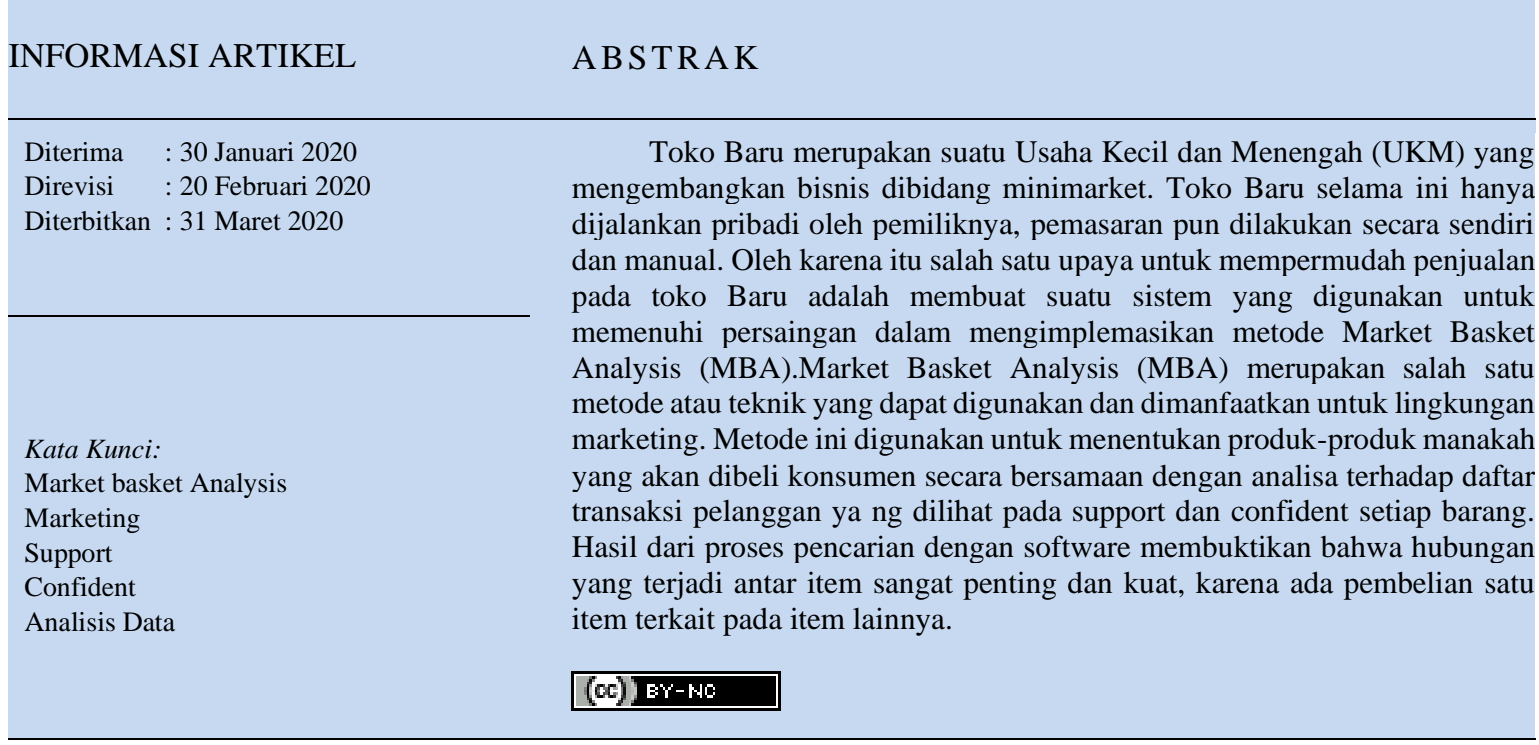

\section{Pendahuluan}

Kemajuan teknologi di bidang basis data masa kini semakin meningkat [1]. Kemajuan teknologi ini memungkinan suatu perusahaan atau organisasi mengumpulkan data dari berbagai sumber dengan mudah dan cepat, sehingga membuat volume data menjadi semakin besar dan terus bertambah [2]-[4]. Semakin besarnya volume data yang ada akan menimbulkan masalah dalam pengklasifikasian atau pengelompokannya. Data yang tersebar tanpa dikelompokkan dengan aturan tertentu tentunya sulit untuk melihat pola pembelian konsumen. Untuk data skala kecil tentunya tidak ada masalah yang signifikan, namun untuk data skala besar sangat dibutuhkan pola dalam proses pembelian, sehingga dibutuhkan pengelompokan data terlebih dahulu [5]-[7].

Dalam dunia bisnis yang selalu dinamis dan penuh persaingan para pelakunya harus selalu memikirkan cara-cara untuk terus survive dan jika mungkin mengembangkan skala bisnis mereka. Untuk mencapai hal itu, ada tiga kebutuhan bisnis yang dapat dilakukan, yaitu penambahan jenis maupun peningkatan kapasitas produk, pengurangan biaya operasional perusahaan, dan peningkatan efektifitas pemasaran serta keuntungan. Agar bisa memenuhi kebutuhan-kebutuhan bisnis di atas banyak cara yang dapat ditempuh salah satunya adalah dengan melakukan analisis data perusahaan pemilihan query yang kurang spesifik akan menghasilkan pencarian yang tidak relevan. Hasil perhitungan pada peringkat awal belum tentu relevan, sehingga dapat dinyatakan pencarian dengan query biasa tidaklah efektif. Jadi, dibutuhkan pengelompokan data untuk mengatasi kendala tersebut. Permasalahan yang muncul adalah bagaimana sistem dapat mengetahui tingkat penjualan yang relevan untuk memenuhi setiap kebutuhan minimarket

Toko Baru merupakan suatu Usaha Kecil dan Menengah (UKM) yang mengembangkan bisnis dibidang minimarket. Toko Baru selama ini hanya dijalankan pribadi oleh pemiliknya, pemasaran pun dilakukan secara sendiri dan manual. Oleh karena itu salah satu upaya untuk mempermudah penjualan pada toko Baru adalah membuat suatu sistem yang digunakan untuk memenuhi persaingan dalam mengimplemasikan metode Market Basket Analysis (MBA). Market Basket Analysis (MBA) merupakan salah satu metode atau teknik yang dapat digunakan dan dimanfaatkan untuk lingkungan marketing. Metode ini digunakan untuk menentukan produkproduk manakah yang akan dibeli konsumen secara bersamaan dengan analisa terhadap daftar transaksi pelanggan. 


\section{Metode}

Association rules merupakan sebuah aturan tertentu atau rules yang menyatakan sebuah hubungan korelasi antara tingkat kemunculan beberapa atribut dalam sebuah database[8]. Bentuk umum dari Association Rules adalah:

$$
\mathrm{A} 1 \ldots . ., \mathrm{An} \rightarrow \mathrm{B}
$$

Yang artinya bahwa pelanggan yang membeli produk A juga mempunyai peluang yang cukup besar untuk membeli produk B, dimana tidak ada batasan pada jumlah dari item-item pada heal ataupun body dari sebuah rule. Bentuk lain yang lebih kompleks dari Association Rule adalah:

$$
\mathrm{A}, \mathrm{C} \rightarrow \mathrm{B}, \mathrm{D}
$$

Yang artinya bahwa pelanggan yang membeli produk $\mathrm{A}$ dan $\mathrm{C}$ juga mempunyai kecenderungan untuk membeli produk B dan D. Salah satu masalah dalam pencarian Association Rule adalah sangat banyaknya kemungkinan ditemukannya rules yang belum tentu merupakan rules yang baik dan dapat dipercaya. Penting tidaknya suatu aturan asosiatif dapat diketahui dengan dua parameter, yaitu support dan confidence. Support (nilai penunjang) adalah persentase kombinasi item tersebut dalam database. Sedangkan Confidence (nilai kepastian) adalah kuatnya hubungan antar item dalam aturan asosiasi.

Analisis asosiasi didefinisikan sebagai suatu proses untuk menemukan semua aturan asosiasi yang memenuhi syarat minimum untuk support (minimum support) dan syarat minimum untuk confidence (minimum confidence). Jika supportnya $\geq$ minimum support dan confidencenya $\geq$ minimum confidence, maka rule tersebut bisa dikatakan sebagai interesting rule. Tahap ini mencari kombinasi item yang memenuhi syarat minimum dari nilai support dalam database. Nilai support sebuah item diperoleh dengan perhitungan seperti berikut.

Setelah semua pola frekuensi ditemukan, barulah dicari aturan asosiasi yang memenuhi syarat minimum untuk confidence dengan perhitungan confidence sebagai berikut :

$$
\begin{aligned}
& \text { support }(\mathrm{A} \cap \mathrm{B})=\frac{\text { jumlah transaksi mengandung } A \text { dan } B}{\text { total jumlah transaksi keseluruhan }} \times 100 \% \\
& \text { Confident }(\mathrm{A} \text { I B })=\frac{\text { jumlah transaksi mengandung } A \text { dan } B}{\text { total jumlah transaksi } A} \times 100 \%
\end{aligned}
$$

Menurut Ngatimin (2013) Salah satu contoh penerapan Association Rule adalah Market Basket Analysis. Association Rule menjadi terkenal karena aplikasinya untuk menganalisa isi keranjang belanja di pasar swalayan, sehingga Association Rule juga sering disebut dengan istilah Market Basket Analysis.

\section{1) Perancangan Inisialisasi Data}

Langkah awal dari sistem yang dibuat adalah memasukkan barang-barang jualan dari toko baru kemudian dijumlah dengan barang yang dibeli untuk mendapatkan nilai support $10 \%$ dan confidence $30 \%$ sehingga dapat diuraikan barang apa saja yang sering dibeli dan yang jarang dibeli. Nilai minimum support dan confidence yang diatur sudah tentukan karena data dianggap sudah benar.

Tabel 1. Dataset item

\begin{tabular}{cl}
\hline No. & \multicolumn{1}{c}{ Item yang dibeli } \\
\hline 1 & $\begin{array}{l}\text { Minyak Goreng, detergen ,pelembut } \\
\text { pakaian }\end{array}$ \\
\hline 2 & detergen, pasta gigi, pembersih lantai \\
\hline.. & $\ldots$ \\
\hline 50 & minyak goreng, pelembut pakaian
\end{tabular}

\begin{tabular}{cl}
\hline No. & \multicolumn{1}{c}{ Item yang dibeli } \\
\hline 51 & $\begin{array}{l}\text { minyak goreng, pasta gigi, pelembut } \\
\text { pakaian }\end{array}$ \\
\hline 52 & $\begin{array}{l}\text { minyak goreng, sabun mandi, pembersih } \\
\text { lantai }\end{array}$ \\
\hline$\ldots$ & $\ldots$ \\
\hline 100 & detergen, sabun mandi,minyak goring
\end{tabular}


Dalam tahap ini data di dapatkan dari pihak Toko Baru. Data yang di dapatkan sebanyak 100 transaksi. Data - data diatas didapatkan kurang lebih 1 tahun yang lalu dikarenakan pada saat pengambilan data, pemilik toko cuma memberikan nama - nama barang tanpa menuliskan tanggal dan tahun transaksi.

Tabel 2. Penjumlahan Item pada Setiap Transaksi

\begin{tabular}{cc}
\hline Transaksi & Item yang dibeli \\
\hline 48 & Minyak Goreng \\
\hline 64 & Detergen \\
\hline 34 & Pelembut Pakaian \\
\hline 54 & Pasta Gigi \\
\hline 19 & Pembersih lantai \\
\hline 5 & Sabun Muka \\
\hline 24 & Sabun Mandi \\
\hline
\end{tabular}

Pada tahap ini dilakukan perhitungan manual dengan cara menentukan frequent itemset pada setiap transaksi.

Tabel 3. Insialisasi Data

\begin{tabular}{cc}
\hline Item & Inisialisasi \\
\hline Minyak Goreng & $\mathrm{A}$ \\
\hline Detergen & $\mathrm{B}$ \\
\hline Pasta Gigi & $\mathrm{C}$ \\
\hline Sabun Mandi & $\mathrm{D}$ \\
\hline Pembersih Lantai & $\mathrm{E}$ \\
\hline Pelembut Pakaian & $\mathrm{F}$ \\
\hline Sabun Muka & $\mathrm{H}$
\end{tabular}

Data diatas menggambarkan bentuk data satu itemset yang terdiri atas atribut sebagai nama item yang ada.

Tabel 4. Insialisasi Data

\begin{tabular}{cc}
\hline Item & Inisialisasi \\
\hline Minyak Goreng & $\mathrm{A}$ \\
\hline Detergen & $\mathrm{B}$ \\
\hline Pasta Gigi & $\mathrm{C}$ \\
\hline Sabun Mandi & $\mathrm{D}$ \\
\hline Pembersih Lantai & $\mathrm{E}$ \\
\hline Pelembut Pakaian & $\mathrm{F}$ \\
\hline Sabun Muka & $\mathrm{H}$ \\
\hline
\end{tabular}


Tabel 5. Perhitungan frequent 1 itemset

\begin{tabular}{ccc}
\hline No. & Item & Support \\
\hline 1. & A & $(48 / 100) \times 100 \%=48$ \\
\hline 2. & B & $(64 / 100) \times 100 \%=64$ \\
\hline 3. & C & $(34 / 100) \times 100 \%=34$ \\
\hline 4. & D & $(54 / 100) \times 100 \%=54$ \\
\hline 5. & E & $(19 / 100) \times 100 \%=19$ \\
\hline 6. & F & $(5 / 100) \times 100 \%=5$ \\
\hline 7. & H & $(24 / 100) \times 100 \%=24$
\end{tabular}

ada.

Data diatas menggambarkan bentuk data satu itemset yang terdiri atas atribut sebagai nama item yang

Tabel 6. Perhitungan frequent 2 itemset

\begin{tabular}{ccc}
\hline No. & Item & Support \\
\hline 1. & AB & $(10 / 100) \times 100 \%=10$ \\
\hline 2. & AC & $(5 / 100) \times 100 \%=5$ \\
\hline 3. & AD & $(9 / 100) \times 100 \%=9$ \\
\hline 4. & BA & $(9 / 100) \times 100 \%=9$ \\
\hline 5. & BC & $(24 / 100) \times 100 \%=24$ \\
\hline 6. & BD & $(5 / 100) \times 100 \%=5$ \\
\hline 7. & BH & $(5 / 100) \times 100 \%=5$ \\
\hline 8. & CA & $(9 / 100) \times 100 \%=9$ \\
\hline 9. & CB & $(11 / 100) \times 100 \%=11$ \\
\hline 10. & DA & $(9 / 100) \times 100 \%=9$ \\
\hline
\end{tabular}

Perhitungan frequent dua itemset di atas menggambarkan bentuk kombinasi dua itemset. Dengan menetapkan nilai minimum support $10 \%$

Tabel 7. Frequent 2 itemset yang memenuhi nilai minimum support

\begin{tabular}{ccc}
\hline No. & Item & Support \\
\hline 1. & AB & $(10 / 100) \times 100 \%=10$ \\
\hline 2. & BC & $(24 / 100) \times 100 \%=24$ \\
\hline 3. & CB & $(11 / 100) \times 100 \%=11$ \\
\hline
\end{tabular}

Perhitungan 2 itemset diatas menggambarkan bentuk data kombinasi 2 itemset dengan menepatkan nilai minimum support $10 \%$. 
Tabel 8. Perhitungan frequent confident

\begin{tabular}{ccc}
\hline No. & Item & Confident \\
\hline 1. & Jika A maka B & $(10 / 48) \times 100 \%=20.8$ \\
\hline 2. & Jika B maka A & $(10 / 64) \times 100 \%=15.6$ \\
\hline 3. & Jika B maka C & $(24 / 64) \times 100 \%=37.5$ \\
\hline 4. & Jika C maka B & $(24 / 34) \times 100 \%=70.5$ \\
\hline
\end{tabular}

Perhitungan itemset diatas menggambarkan bentuk data kombinasi nilai confident dengan menetapkan nilai minimum confident $30 \%$

\section{Hasil dan Pembahasan}

Perhitungan itemset diatas menggambarkan bentuk data kombinasi nilai support dan nilai confident dengan menetapkan nilai minimum support $10 \%$ dan minimum confident $30 \%$, diketahui bahwa hasil tersebut sama dengan hasil perhitungan yang penulis lakukan pada tahap perancangan, yaitu terdapat 3(tiga) buah rule. Rulerule yang dihasilkan yaitu :

1. Jika membeli Minyak Goreng maka akan membeli Detergen dengan support $10 \%$ dan confidence $21 \%$.

2. Jika membeli Detergen maka akan membeli Pasta Gigi dengan support 24\% dan confidence 37.5\%.

3. Jika membeli Pasta Gigi maka akan membeli Detergen dengan support 11\% dan confidence 70.5\%.

\section{Kesimpulan}

Berdasarkan hasil penelitian ini maka penulis dapat menarik kesimpulan, yaitu :

1. Dengan menerapkan minimum support sebesar $10 \%$ dan confident sebesar $30 \%$ pada Metode Market Basket Analysis maka diperoleh output sebanyak 4 rule.

2. Berdasarkan 4 rule output dilakukan uji akurasi dan presisi dan memperoleh nilai sebesar $0.7(70 \%)$ dan $0.78(78 \%)$.

\section{Daftar Pustaka}

[1] N. Fadhillah, Huzain Azis, and D. Lantara, "Validasi Pencarian Kata Kunci Menggunakan Algoritma Levenshtein Distance Berdasarkan Metode Approximate String Matching," Pros. Semin. Nas. Ilmu Komput. dan Teknol. Inf., vol. 3, no. 2, pp. 3-7, 2018.

[2] L. Nurhayati and H. Azis, "Perancangan Sistem Pendukung Keputusan Untuk Proses Kenaikan Jabatan Struktural Pada Biro Kepegawaian,”Semin. Nas. Teknol. Inf. dan Multimed., pp. 6-7, 2016.

[3] Rosmasari et al., "Usability Study of Student Academic Portal from a User's Perspective," Proc. - 2nd East Indones. Conf. Comput. Inf. Technol. Internet Things Ind. EIConCIT 2018, pp. 108-113, 2018.

[4] H. Azis, R. D. Mallongi, D. Lantara, and Y. Salim, "Comparison of Floyd-Warshall Algorithm and Greedy Algorithm in Determining the Shortest Route," Proc. - 2nd East Indones. Conf. Comput. Inf. Technol. Internet Things Ind. EIConCIT 2018, pp. 294-298, 2018.

[5] A. A. Karim, H. Azis, and Y. Salim, "Kinerja Metode C4.5 dalam Penyaluran Bantuan Dana Bencana 1,” Pros. Semin. Nas. Ilmu Komput. dan Teknol. Inf., vol. 3, no. 2, pp. 84-87, 2018.

[6] A. Fitria and H. Azis, “Analisis Kinerja Sistem Klasifikasi Skripsi menggunakan Metode Naïve Bayes Classifier,” Pros. Semin. Nas. Ilmu Komput. dan Teknol. Inf., vol. 3, no. 2, pp. 102-106, 2018.

[7] M. M. Baharuddin, T. Hasanuddin, and H. Azis, “Analisis Performa Metode K-Nearest Neighbor untuk Identifikasi Jenis Kaca,” Ilk. J. Ilm., vol. 11, no. 28, pp. 269-274, 2019.

[8] N. Kurniati, I. S. Sitanggang, and I. Hermadi, "Optimasi Aturan Asosiasi Multidimensi menggunakan Algoritme Genetika untuk Klasifikasi Kemunculan Titik Panas Multidimension Association Rule Optimization using Genetic Algorithm for hotspot occurrence Classification,” vol. 4, pp. 42-52. 